Family Adaptability and Cohesion Evaluation Scale - Version IV (FACES IV): Validation study in the Portuguese population

\begin{tabular}{|r|l|}
\hline Journal: & Journal of Marital and Family Therapy \\
\hline Manuscript ID & Draft \\
\hline Manuscript Type: & Original Article \\
\hline Keywords: & $\begin{array}{l}\text { Assessment/Diagnosis < Clinical, Families < Populations, Classical < } \\
\text { Theory/Model }\end{array}$ \\
\hline \multicolumn{2}{|l}{} \\
\hline
\end{tabular}




\title{
FAMILY ADAPTABILITY AND COHESION EVALUATION SCALE - VERSION IV (FACES IV): VALIDATION STUDY IN THE PORTUGUESE POPULATION
}

\begin{abstract}
The present study addresses the psychometric properties of the Portuguese translation and adaptation of the Family Adaptability and Cohesion Evaluation Scale - version IV (FACES IV). The sample included 1089 individuals from 387 nuclear families, with an average age of 36 years. Besides its sociodemographic heterogeneity, the sample also included participants in various stages of the family life cycle and belonging to different family subsystems. We found overall good to moderate psychometric properties, namely adequate internal consistency, convergent validity, and discriminant ability. However, rigid and enmeshed scales presented weaker results. Normative expectations and cultural bias are discussed. FACES IV appears to be a valid and reliable measure of family dynamics, suitable for research and clinical purposes within the Portuguese context. However, further studies need to be carried out regarding the instruments' properties in tapping extremely high cohesion (enmeshment) and low flexibility (rigidity) levels.
\end{abstract}

Key-words: Family Adaptability and Cohesion Evaluation Scale, Validation, Family Functioning Assessment, Family Life Cycle 


\section{FAMILY ADAPTABILITY AND COHESION EVALUATION SCALE - VERSION IV (FACES IV): VALIDATION STUDY IN THE PORTUGUESE POPULATION}

\section{INTRODUCTION}

This article presents the translation and validation of the FACES IV (Family Adaptability and Cohesion Evaluation Scale - version IV) for the Portuguese population, a self-report measure of family functioning based on the Circumplex Model of Marital and Family Systems (Olson, Sprenkle, \& Russell, 1979; Olson, 1993). From 1977 through 1999, approximately 450 empirical studies and 75 reviews and commentaries were published involving different FACES versions, making it one of the most widely used and studied family/marital assessment instruments (Kouneski, 2000). Ever since its inception, both the model and the scale were submitted to extensive revisions and alterations, which we will briefly address.

The Circumplex Model integrates three dimensions of family behavior, which emerged from a conceptual clustering of more than fifty concepts (Olson et al., 1989; Olson, 1993) developed in different social science fields (e.g., Psychiatry, Sociology, Small-group studies, Anthropology) to describe marital/family dynamics: cohesion, flexibility (adaptability in earlier versions of the model), and communication. Family cohesion was defined as "the emotional bonding that family members have toward one another". The variables or concepts used to diagnose and measure cohesion were "emotional bonding, boundaries, coalitions, time, space, friends, decision making, and interests and recreation." The second dimension, family flexibility or adaptability, was defined as "the ability of a marital or family system to change its power structure, and relationship rules in response to situational and developmental stress." The concepts used to measure and describe this 
dimension were taken from social science disciplines, particularly family sociology, and included "family power (assertiveness, control, discipline), negotiation styles, role relationships, and relationship rules" (Olson et al., 1989, p. 48). Finally, communication was considered a facilitating dimension, allowing couples and families to move on the other two dimensions and its measurement focused "listening skills, speaking skills, self-disclosure, clarity, continuity-tracking, and respect and regard" (Olson, 1993, p. 108).

While attempting to bridge existing gaps between research, theory, and practice, the Circumplex Model provided a systematic and integrative theoretical model for the myriad of concepts used in the study of (ab)normal family processes, that allowed hypotheses to be deduced and tested (Olson et al., 1989). The main hypothesis derived from the Circumplex Model, also known as the curvilinear hypothesis, is that balanced or central levels of cohesion and flexibility translate into optimal family functioning. At the same time, extreme or unbalanced values on these dimensions are associated with families/couples experiencing problems or with higher family vulnerability.

Olson, Bell, and Portner in 1978 developed the original version of FACES, which consisted of a self-report instrument with 111 items that included three scales: cohesion, flexibility, and social desirability (Alexander et al., 1984; Kouneski, 2000). The scale underwent several modifications to improve its psychometric qualities, resulting in FACES II (Olson, Portner, \& Bell, 1982) and FACES III versions (Olson, Portner, \& Lavee, 1985; Olson, 1986). Empirical studies with these versions provided support to their ability for differentiating patterns of family functioning across a variety of clinical situations (e.g., Prange et al., 1992; Kashani et al., 1995; Place et al., 2005), and they have gained wide acceptance across the years, even though some authors argue that during the early 1990s, 
interest in the dimensional evaluation of family functioning waned with the increasing popularity of family narratives (Place et al., 2005).

The main challenge came from the fact that FACES II and III versions presented a linear relation with (un)healthy family functioning and adjustment, whereas the Circumplex Model predicted a curvilinear relation (Olson, 2011). High scores in the cohesion and flexibility scales seemed to reflect balanced family functioning, and low levels were associated with disengaged and rigid family functioning (Kouneski, 2000). This meant that the scales were not able to classify enmeshed or chaotic families adequately. A new version of FACES was developed to address these issues. FACES IV has a different organization with six scales: two balanced scales (cohesion and flexibility) and four unbalanced scales (disengaged, chaotic, enmeshed, and rigid). Family Satisfaction (FSS) and Family Communication (FCS) were also included as companion scales (Olson \& Gorall, 2003). In 2008, FACES IV was classified as an "approaching well-established" measure of general family functioning (Alderfer et al., 2008), but since then, several studies concerning its psychometric properties have surfaced. Results from the validation study by Olson (2011), indicated that the six scales were valid and reliable, with high levels of concurrent, construct and discriminant validity (although Enmeshed and Rigid scales had the lowest correlations with the validity scales, warranting further work).

Adaptation and validation studies of FACES IV have also been conducted in Italy (Baiocco et al., 2013), Uruguay (Ball et al., 2009), Hungary (Mirnics et al., 2010), Spain (Rivero et al., 2010), Greece (Koutra et al., 2012), Iran (Mazaheri et al., 2014), Poland (Margasiński, 2015) and Portugal (Pereira \& Teixeira, 2013; Gomes et al., 2019), showing overall good psychometric properties and cross-cultural applicability. The first Portuguese study was conducted with a sample of 214 adult caregivers (aged $\geq 18$ years) of patients 
undergoing chemotherapy, limiting the generalization of results to more diverse families (Pereira \& Teixeira, 2013). As previous studies suggested, enmeshed and rigid scales were also found to be empirically weaker. The authors suggested additional validation studies with more diverse samples in order to improve the predictive validity and application in the clinical work of FACES IV (Pereira \& Teixeira, 2013). Another study conducted in Portugal effectively focused on a different population of married couples with children where one parent had schizophrenia but did not analyze the psychometric properties of the instrument (Carvalho et al., 2014). The second validation study addressed the limitations found in the preceding one, presenting a significative leap forward with the employment of a systematic process of validation (Gomes et al., 2019). The factor analysis conducted led the authors to an item reduction process that resulted in a final 24 item solution, with four items per scale. Despite its groundbreaking nature and undeniable contribution to family research, this study also had its limitations. The instruments used to analyze convergent validity were not specific measures of family functioning, and discriminant analysis was also limited. The authors signaled that women's perceptions of family functioning were probably over-represented, but participants with university degrees were also over-represented, reaching almost twothirds of the sample (64.5\%). This last feature restricts the sample representativeness regarding the Portuguese population because, according to OECD (2019) data, only $25 \%$ of Portuguese adults (25-64 years old) completed tertiary education. Still regarding the sample's properties, certain stages of the individual life cycle were not contemplated, namely adolescence and old age (the age range was $19-57$ years). Finally, while including participants in different family subsystems and family life cycle stages, it was not evaluated if their perceptions of family dynamics differed. This limitation not only impairs the Gomes et al. (2019) study but many other validations. Some studies account for differences between 
family members’ perspectives (e.g., Margasiński, 2015), but none addresses developmental influences on the scales scores. Bearing in mind that the Circumplex Model posits expectable changes in cohesion and flexibility levels throughout family development (Olson et al., 1989), it is puzzling how family life cycle stages are one of the least researched areas with FACES (Kouneski, 2000). Therefore, the present study aims to complement preceding validation efforts by providing further data regarding FACES IV psychometric properties and addressing their limitations.

\section{Objectives}

Considering the promising relevance of FACES IV to assess family functioning, the aims of the present study were its translation, cultural adaptation, and validation for the Portuguese population. The specific goals included: i) analyze the psychometric properties of FACES IV, focusing specifically its factor structure, reliability, and correlations between scales; ii) analyze the instruments' convergent validity through the analysis of the correlations between FACES IV scales and criterion scales; iii) examine the influence of sociodemographic and family variables on the perception of family functioning; iv) analyze the discriminating ability of the six FACES IV scales.

\section{METHODS}

\section{Participants}

Participants were recruited through convenience and snowball sampling procedures, starting with a seed of 55 graduate and undergraduate students in Psychology and Clinical Psychology of the Miguel Torga Institute of Higher Education, Coimbra, Portugal. Each of these students underwent a brief course that addressed the instruments' objectives and 
guidelines for correct administration, and applied the protocol to a minimum of five different families.

The sample was comprised of 1089 individuals from 387 nuclear families. The average age of participants was 36 years $(\mathrm{SD}=15.05)$, with a $12-83$ years range. There was a relatively even gender (male/female) and area of residence (urban/rural) proportion. One third had secondary education, and two-thirds were currently employed/working. All the occupations included in the Portuguese Classification of Occupations of 2010 (CPP/2010) were represented, and the average income was $1618 €(S D=961.59 €)$. Half of the participants were married (or cohabiting), and more than one third was single. About two-thirds were at the "Family with adult children" life cycle stage, but the remaining stages were also represented. Approximately half belonged to the parent subsystem; one third belonged to the child (and/or sibling) subsystem, and the remaining were only part of the couple subsystem (Table 1).

(insert Table 1)

\section{Procedures}

Permission was granted from the authors of the original FACES IV to translate and validate the scale for the Portuguese population. The translation process followed the guidelines recommended by Olson (n.d.) and those described by Beaton, Bombardier, Guillemin, and Ferraz (2000) for the translation and cultural adaptation of self-report measures, which aim to preserve the content validity of instruments across different cultural settings. This process included six independent translators with extensive knowledge in 
Psychology and awareness of the fundamental concepts of FACES IV (some of them family therapists of the Portuguese Family Therapy Society).

Participants were informed of the purposes of the study, the possibility of accessing results (and of their withdrawal), and the confidentiality of responses. All signed an informed consent form. Permission from the ethics committee of the Miguel Torga Institute of Higher Education was also granted.

\section{Measures}

Sociodemographic and Family Questionnaire. This structured questionnaire allowed the collection of sociodemographic information pertaining the respondent (e.g., sex, age, marital status, education, employment status) and detailed information regarding their family (nuclear/cohabiting family composition, the role of respondent in the family, number of children, among others).

FACES IV Package. The FACES IV Package includes the six scales from the Family Adaptability and Cohesion Evaluation Scales IV (FACES IV), the Family Communication Scale (FCS), and the Family Satisfaction Scale (FSS). This set of self-report measures can be completed by all family members with a minimum of 12 years of age and comprises a total of 62 items. FACES IV measures family functioning according to the Circumplex Model and includes a total of 42 items that participants rate in a five-point Likert-type format. These are distributed among two balanced scales (Cohesion and Flexibility) and four unbalanced scales (Enmeshed, Disengaged, Chaotic and Rigid) with seven items each. The Family Communication Scale (FCS) is a 10-item measure (with a 7-point Likert-type format) that assesses communication in family systems. Better family communication is usually an asset of balanced systems (Olson, 1993; Olson \& Gorall, 2003). The FCS was used to assess 
convergent validity in the Portuguese validation studies of the FACES IV (Pereira \& Teixeira, 2013; Gomes et al., 2019) and the Italian study (Baiocco et al., 2013). The Family Satisfaction Scale (FSS) is a self-report measure designed to assess the level of satisfaction that family members have regarding family functioning. It is a ten-item Likert-type scale, with higher values indicating that family members are happy with their family system. Internal consistency (alpha reliability) was .93 (Olson, 2011). The FSS was used as a criterion validity scale in the original study of the FACES IV scales (Olson, 2011) and the Portuguese and Italian studies (Baiocco et al., 2013; Pereira \& Teixeira, 2013; Gomes et al., 2019).

Self-Report Family Inventory - Version II (SFI-II). The SFI was developed by Beavers, Hampson, and Hulgus (1985) as a self-report measure to address constructs associated with the Beavers Systems Model of Family Functioning (Beavers, 1982; Beavers \& Hampson, 1993). The Self-Report Family Inventory: Version II (SFI-II) is a 36-item measure of perceptions of family functioning in five areas: Health/Competence, Conflict, Cohesion, Leadership, and Emotional Expressiveness (Beavers \& Hampson, 1990). Cronbach's alpha for the total scale was reported as between .84 and .93 , and there is evidence that supports test-retest reliability and construct validity (good discriminant abilities and convergent validity with other self-report family measures) (Green \& Bagarozzi, 1987; Tutty, 1995; Grotevant \& Carlson, 1989; Beavers \& Hampson, 2000). For comparison and validation, and following the original validation study by Olson (2011), only the Health/Competence subscale was used, because it was found to be closely related to general family functioning, namely to family cohesion and adaptability/flexibility (Beavers et al., 1985; Tutty, 1995). The Portuguese translation of the SFI-II used in this study revealed good psychometric properties, with Cronbach alpha values of .93 for the total scale and .91 for the Health/Competence subscale. 
Family APGAR. Developed by Smilkstein (1978), the Family APGAR is a brief fiveitem screening instrument, based on family systems theory and coping theory, that provides an overview of the subjects' perception of family functioning (Grotevant \& Carlson, 1989). The instrument possesses good internal consistency reliability, with Cronbach alphas ranging from .80 to .86 (Smilkstein et al., 1982), and discriminant ability (Good et al., 1979). It also presents construct-related validity, suggesting a reliable and valid measure of family function, suitable for clinical practice and research (Good et al., 1979). The Portuguese version was translated and validated by Agostinho and Rebelo (1988), and in the present study revealed good internal consistency reliability properties (Cronbach's alpha $=.77$ ).

\section{Data Analysis}

All statistical analysis was performed using SPSS v25 (IBM SPSS Statistics) and AMOS v18 (IBM SPSS Statistics) software. Descriptive statistics were calculated for both sociodemographic variables and FACES scales' scores. The instrument factor structure was studied using Principal Component Analysis (PCA) with Varimax Rotation. Kaiser-MeyerOlkin $(K M O)$ and Bartlett's sphericity tests were used to determine the adequacy of the data set to factor analysis. To further test the suitability of the six-factor model described in the literature, we removed items with poor factor loadings. Through additional Exploratory Factor Analysis (EFA), we reached a balanced instrument with four items per dimension, that was subjected to Confirmatory Factor Analysis (CFA). The maximum likelihood estimation method was used, considering four goodness-of-fit indicators: Tucker-Lewis Index $(T L I)$, Comparative Fit Index $(C F I)$, and Root Mean Square Error Approximation (RMSEA). Cronbach's alpha coefficient was used to measure internal consistency. Pearson correlation coefficient was employed to evaluate the association between FACES scales, and 
between these and validation scales. Differences in FACES scores according to sociodemographic and family variables were assessed using Student $t$-tests (two groups) and unidirectional ANOVAs / Welch (more than two groups) followed by Tukey HSD/GamesHowell posthoc tests. Finally, for assessing the instruments' predictive validity of problematic family functioning, a discriminant analysis was performed. P-values less than .05 were considered statistically significant.

\section{RESULTS}

\section{Factor analysis}

The 42 FACES IV items were subjected to factor analysis using PCA with Varimax Rotation. The Kaiser-Meyer-Olkin value was 0.91, and Bartlett's sphericity test was statistically significant $(p<.001)$. Taking as guidelines the solutions described by Olson (2011), we forced the extraction of 6 and 4 factors. The results of these analyses were not always coincident with those of the original validation study (Olson, 2011). However, the first factor to emerge in all tested solutions emphasized the balanced scales items (cohesion and flexibility), all with positive factorial saturation above .30 . This result points to a clear differentiation between balanced and unbalanced scales, representing healthy and unhealthy family functioning, which was one of the primary reasons behind the development of the instruments' fourth version.

Following the methodological procedures of Rivero et al. (2010) and Gomes et al. (2019), which presented reduced 4-item per scale solutions, we performed several EFAs, verifying which items to retain and excluding those with inferior factor loadings. The results emanating from these procedures similarly led to a refined model that represents a balanced instrument with four items per latent variable. Construct validity was supported by the quality 
of goodness-of-fit indices of the CFA $(\chi 2 / g l=4.047, R M S E A=.053, N F I=.84, C F I=.902$, $G F I=.93)$

However, considering that there were several discrepancies in the retained items between this study and Gomes et al. (2019) (of the 24 items in each solution, only 14 were coincident), and taking into account the panel of experts assessment of the items during translation, that they were representative of the family dimensions purported to evaluate, we opted to retain all 42 items, conducting the ensuing statistical analysis with the full scale.

\section{Internal consistency, average scale scores, and intercorrelations between scales}

The results of the internal consistency assessment for the six scales were relatively modest when compared with previous studies that found very good or good alpha values (Olson, 2011; Pereira \& Teixeira, 2013) but similar to other validations (Baiocco et al., 2013; Koutra et al., 2012). Cronbach's alpha values ranged from a maximum of .77 for balanced cohesion to a minimum of .58 in the enmeshed scale. Olson's initial validation (2011), the Greek and Portuguese studies (Koutra et al., 2012; Gomes et al., 2019) also found the lowest alpha values in the enmeshed scale (Table 2).

Balanced cohesion and flexibility presented average mean scores considerably superior to the four unbalanced scales $(M=28.03$ and $M=26.06$, respectively). Regarding the unbalanced scales, disengaged and chaotic converged in the 15 points average, but enmeshed and rigid presented higher mean scores, around 20 points. This difference in the average mean scores of unbalanced scales was also found in the study of Pereira and Teixeira (2013), probably signifying that Portuguese families tend to perceive a higher degree of enmeshment and rigidity. The fact that this pattern does not emerge consistently in other countries provides further support for the cultural specificity hypothesis. For example, in the 
Greek and Italian validation studies, the enmeshed scale presented one of the lowest average scores among the unbalanced scales (but Italians and Greeks also tended to characterize their family functioning as rigid) (Baiocco et al., 2013; Koutra et al., 2012). However, it should be noted that in the Portuguese Gomes et al. (2019) study, the highest average scores of unbalanced scales were rigid and chaotic, but these stemmed from the analysis of a smaller number of items.

Correlation analyses were performed to assess the relationships between the six scales (Table 2). As expected, the two balanced scales (cohesion and flexibility) were highly correlated $(r=.72)$. Olson (2011) and Pereira and Teixeira (2013) found similar results, hypothesizing that these indicate that healthy family functioning is manifested through concordance in balanced scales. High significant correlations between balanced scales were also found in other validation studies (Koutra et al., 2012; Mirnics et al., 2010; Gomes et al., 2019), being one of the most recurrent and therefore empirically supported results.

There was a high and statistically significant negative correlation between balanced cohesion and disengaged $(r=-.65)$ and a low positive correlation between balanced cohesion and enmeshed $(r=.19)$. Balanced flexibility presented a moderate and statistically significant correlation with chaotic $(\mathrm{r}=-.39)$ and a low positive correlation with rigid $(r=.14)$. Enmeshment and rigidity seemed to be positively connected to balanced functioning.

Regarding relations between the two subsets of scales, it should be noted that the two unbalanced scales of rigid and enmeshed showed a moderate and statistically significant positive correlation $(\mathrm{r}=.41)$; the same applies to the disengaged and chaotic scales $(r=.51)$. Pereira and Teixeira (2013) found that families characterized by disengagement lean towards chaotic functioning, and vice-versa. Our results add that rigidity and enmeshment tend to cooccur, being in a significant relationship that also emerged in the Portuguese, Greek, and 
Hungarian validation studies (Koutra et al., 2012; Mirnics et al., 2010; Gomes et al., 2019). Balanced flexibility presented a negative correlation with disengaged $(r=-.52)$, and balanced cohesion presents a negative correlation with chaotic $(r=-.44)$. With low or very low correlation values, we found positive correlations between balanced flexibility and enmeshed $(r=.18)$. Once again, enmeshment seemed to be positively associated with healthy family functioning.

(insert Table 2)

\section{Convergent validity}

Correlations with three validation scales were conducted to assess the convergent validity of the six FACES IV scales: FSS, SFI-II Health/Competence subscale, and APGAR (Table 3). It should be noted that for the SFI-II Health/Competence subscale, higher scores are an indicator of greater problems within the family system.

As expected, balanced cohesion and flexibility scales were strongly and negatively correlated with the SFI-II Health/Competence subscale $(r=-.71$ and -.62). The scales designed to assess disengaged and chaotic functioning presented positive correlations of large/moderate magnitude $(r=.64$ and .48$)$. Rigidity did not reveal a significant relation, whereas the enmeshment scale presented a low negative, but still statistically significant, correlation $(r=-.18)$.

Similar results emerged with the FSS. High and positive correlations were found between balanced scales and the FSS ( $r=.57$ and .62$)$, indicating that healthy cohesion and flexibility are closely associated with increased family satisfaction. In the opposite direction, 
higher values in the disengaged and chaotic scales were connected with less satisfaction $(\mathrm{r}=$ -.53 and -.37$)$.

Several statistically significant correlations were found between the FACES scales and APGAR, but with lower values when compared to the first two validation scales. Regarding APGAR, all the FACES scales manifested the same general trends reported: balanced scales presented significant positive correlations $(r=.11$ and .14$)$; disengaged and chaotic presented negative ones $(r=-.17$ and -.15$)$.

As with the original study by Olson (2011), the validity of the two balanced scales and the disengaged and chaotic scales was highly supported. Enmeshed and rigid scales presented weaker results. The convergent validity analysis of FACES IV by Pereira and Teixeira (2013) also found non-significant correlations between the enmeshed and rigid scales and the validation scales. Gomes et al. (2019) only found poor psychometric properties in the rigid scale.

(insert Table 3)

\section{Sociodemographic determinants of family functioning}

Contrary to Pereira and Teixeira (2013), but aligned with other validations (Mirnics et al., 2010; Gomes et al., 2019), significant associations with age and gender were found. Women reported more balanced cohesion and less disengagement than men, and several differences were found between age groups, except in the rigid scale (Table 4). Younger subjects (age $\leq 24)$ tended to perceive lower levels of balanced functioning (cohesion and flexibility), and higher levels of unbalanced functioning (enmeshed, disengaged, and chaotic). Subjects in the age range of 35-44 presented the highest scores of balanced cohesion 
and flexibility, the lowest values of disengaged and chaotic functioning, but also perceived the highest levels of enmeshed and chaotic functioning. Older subjects (age $45 \geq$ ) perceive more disengagement in their families, with values similar to their younger counterparts.

Regarding employment status, employed/working subjects tended to perceive higher degrees of balanced cohesion and flexibility than those who were students. They also perceived less disengagement than students and retired subjects (Table 4). Other studies did not find significant differences between younger or older, employed, or unemployed participants (Koutra et al., 2012).

The sociodemographic variable that appears to hold a higher correlation with the perception of family functioning was education (Table 4). All the FACES IV scales, except chaotic, present the same pattern: higher echelons of educational attainment appear connected to lower values in the unbalanced scales and higher levels of balanced functioning. These differences were more pronounced than those found in the study by Pereira and Teixeira (2013), where less education only showed a statically significant impact with higher scores in the enmeshed and chaotic scales.

(insert Table 4)

\section{Family subsystems and life cycle stages}

Several significant differences, according to family subsystem membership and life cycle stage, were found (Table 5). Regarding family subsystems, one of the most striking features is the lack of agreement between child and parent subsystems on all cohesion scales and in the balanced flexibility scale. Members of parent subsystems tend to perceive more balanced cohesion and flexibility, less disengagement, and more enmeshment, than members 
of child subsystems. Those that belong to the couple subsystem only differ significantly in balanced flexibility in comparison to members of child subsystems. Their average scores were similar to parent subsystems, except on chaotic functioning, where they registered the highest average score of all three groups. These results point to a pronounced parent-child discrepancy in family functioning perception, consistent with previous research (Olson et al., 1989; Margasiński, 2015).

As predicted by the Circumplex Model, people at various stages of the family life cycle report different levels of cohesion and flexibility. The patterns found for both balanced scales closely resemble the results obtained by Olson et al. (1989). Balanced cohesion is higher in the early stages, reaching its apex in families with school-age children, and then descending in the following stages. Balanced flexibility is at its maximum in the young couple without children's stage but immediately decreases during the childbearing stage. There is a statistically significant decline in flexibility between families with school-age children and adolescents, and the average scores drop even further, reaching its minimum value in families with adult children.

These results are mostly congruent with individual and family development theoretical perspectives. For example, cohesion reaches its ebb during the last stages, when families are in the process of separation-individuation, and adult children are experiencing even greater freedom and autonomy (Olson et al., 1989), often associated with higher education academic pursuits outside the family's area of residence. Taking into account these developmental tasks does not come as a surprise that families' sense of togetherness and closeness changes and might be perceived as decreasing and even more disengaged (Olson et al., 1989). Flexibility is highest among childless young couples. At this stage, couples are negotiating roles, rules, and patterns and constructing their model of relationship. The major 


\begin{abstract}
demand is related to their ability to be flexible so that an idiosyncratic way of being a couple can emerge.
\end{abstract}

(insert Table 5)

\title{
Discriminant analysis
}

Since the entire sample was drawn from the general population and we had no specific criteria or clinical situation identified that allowed the definition of "problem group(s)," to assess FACES' discriminant ability we followed the procedure by Olson (2011) and created groups based on the scores obtained by each person on the validation scales. When subjects scored above $50 \%$ (or $40 \%$ ) on the Health/Competence subscale of SFI-II (where lower values indicated poor family functioning) and below $50 \%$ (or $40 \%$ ) in the FSS, they were assigned to a "problem group." Scores below 50\% (or 40\%) in the APGAR scale also determined the subjects' placement in a "problem group."

As expected, the greater discriminant ability was found in the top versus bottom $40 \%$ groupings (see columns 2 and 4 in Table 8). In these groups and both scales, the range of correct placement ranged from $50.4 \%$ to $85.1 \%$, with an average for the six FACES scales of $66.91 \%$. The scales that presented greatest discriminant ability were balanced cohesion (85.1\% correct placement on SFI-II/FSS and $72.3 \%$ on APGAR), disengaged $(81.4 \%$ on SFIII/FSS and $68.1 \%$ on APGAR) and balanced flexibility $(80,2 \%$ on SFI-II/FSS and $72.8 \%$ on APGAR). The chaotic scale presented moderate values and the weakest results were found in the enmeshed and rigid scales,

When the six scales were used together, predictive accuracy ranged from $72.4 \%$ to 86.6\%. The Cohesion Ratio score presented the greatest predictive accuracy when compared 
with the Flexibility Ratio, and the Circumplex Total Ratio discriminant ability ranged from a minimum of $72.3 \%$ to a maximum of $85.1 \%$.

(insert Table 6)

\section{DISCUSSION}

This study presents a major contribution to family systems research since it was the first FACES IV validation study conducted in Portugal to include a large and heterogeneous sample drawn from the general population, complementing existing literature (Pereira \& Teixeira, 2013; Gomes et al., 2019) on this important self-report family assessment questionnaire. Besides the large sample size and the participants' heterogeneity, and like the Greek validation endeavor (Koutra et al., 2012), one of the strengths of the present study was also the use of standardized procedures for the translation and cross-cultural adaptation of the original questionnaire. Another relevant and original contribution was the analysis of family functioning according to family subsystem membership and in different stages of the family life cycle. Besides providing further empirical support to the parent-children (particularly, adolescent children) disagreement in family functioning perception (Olson et al., 1989; Margasiński, 2015), our results suggest that FACES IV detects changes in cohesion and flexibility across the family life cycle, consistent with normative developmental tasks and processes highlighted by family theorists, and with the developmental hypothesis derived from the Circumplex Model.

We found overall good to moderate psychometric properties, meaning that FACES IV scales appear to measure, reliably and validly, the full-dimensional spectrum of cohesion and flexibility defined by the Circumplex Model (Olson, 2011), with adequate levels of 
construct, convergent and discriminant validity. As in the original validation study (Olson, 2011), content validity for the six scales was based on the scholarly opinion of senior family therapists of the Portuguese Family Therapy Society involved in the translation procedures, that described items as adequately representing evaluated dimensions.

However, the Portuguese version of FACES IV presented an uneven balance between scales regarding their psychometric properties, which warrants further discussion. Balanced, disengaged, and chaotic scales present overall better properties; enmeshed and rigid scales reveal weaker properties. Previous validation studies conducted in Portugal (Pereira \& Teixeira, 2013; Gomes et al., 2019) also revealed similar findings.

These results might be due to Portuguese cultural specificities, namely its traditional values and manifest ideological familism, that emphasizes affective closeness, frequent contacts between family members, explicit solidarity norms and reliability on the availability of family support, tending to the exclusion of other types of social relations (Portugal, 2011). While working with Portuguese immigrants in the United States, Araújo-Lane (2005) identified similar cultural traits, such as marked respect for authority and hierarchies, the importance conceded to honor, that sometimes makes a family seem rigid and often induces family members to stay together for its sake, and difficulty in sharing problems outside the confines of the immediate family. Therefore, a certain degree of enmeshment and rigidity seems to characterize "normal" family functioning in the Portuguese context and occasionally approximates these dimensions to "healthy" family functioning. Olson et al. (1989) also addressed this issue, cautioning that normative expectations and cultural bias could compromise curvilinearity.

However, the cultural background might not entirely account for these results. They may also be due to the inherent limitations of self-report inventories in evaluating certain 
aspects of family functioning. This hypothesis might explain why other validation studies also found the weakest psychometric properties in the unbalanced scales, particularly in the enmeshed and/or rigid scales (Ball et al., 2009; Pereira \& Teixeira, 2013; Margasiński, 2015; Olson, 2011). Some authors caution that strong beliefs about how the family should interact, as well as family loyalty and protection factors, could influence the subjects' responses to paper-and-pencil scales in a socially desirable way, distorting and biasing collected data (Fisher, 1982; Tutty, 1995). Therefore, we suggest the development of a FACES IV version for therapists and professionals, to address both insiders' and outsiders' views, even though we acknowledge that they might only provide another partial perspective, just as limited and distanced from the elusive "true picture" as family members" perceptions (Tutty, 1995). This new instrument would allow the development of a body of research theoretically grounded on the Circumplex Model and focused on the perspectives that professionals hold about their clients' family functioning across a wide variety of situations.

Future studies with clearly identified clinical samples would be useful to provide an adequate test of FACES IV discriminant ability. It would also be relevant to the development of FACES IV to address different ethnic and cultural backgrounds, emerging family forms and challenges, and other stages of the expanded family life cycle, such as late middle age, retirement or later life families (Olson et al., 1989; McGoldrick et al., 2014).

Snowball sampling procedures entail limitations, and might account for some skewing in the representativeness of certain sociodemographic and family groups (e.g., some occupations are underrepresented, and families with adult children are overrepresented), but participants in virtually all the stages of the individual (from early adolescence onwards) and family life cycle, and from different family subsystems, were included. As such, while it may be premature to consider the average FACES IV scales scores obtained in the present study 
as national norms for the Portuguese population, they are nonetheless a stepping stone in this direction. As stated earlier, we found a distinctive pattern of mean scores that presented similarities with another validation study conducted in Portugal that kept the original 42 items (Pereira \& Teixeira, 2013), but not with the results described by Gomes et al. (2019) that used a shorter version of FACES IV. This pattern is distinct from other countries' results, entailing discrepancies in the average values of the unbalanced scales, with disengaged and chaotic presenting lower scores than rigid and enmeshed. While more substantial normative data is not obtained, researchers and clinicians in the Portuguese national context should take into account that differences between these two subsets of unbalanced scales should not be immediately interpreted as clinically significant or as a deviation from the norm.

\section{REFERENCES}

Agostinho, M., \& Rebelo, L. (1988). Família: do conceito aos meios de avaliação. Revista Portuguesa de Clínica Geral, 6, 6-17.

Alarcão, M. (2000). (Des)equilíbrios familiares: Uma visão sistémica. Coimbra: Quarteto Editora.

Alderfer, M. A., Fiese, B. H., Gold, J. I., Cutuli, J. J., Holmbeck, G. N., Goldbeck, L., ... Patterson, J. (2008). Evidence-based assessment in pediatric psychology: Family measures. Journal of Pediatric Psychology, 33 (9), 1046-1061. https://doi.org/10.1093/jpepsy/jsm083

Alexander, B. B., Johnson, S. B., \& Carter, R. L. (1984). A Psychometric Study of the Family Adaptability and Cohesion Evaluation Scales. Journal of Abnormal Child Psychology, 12(2), 199-208. https://doi.org/10.1007/BF00910663

Araújo-Lane, Z. (2005). Portuguese Families. In M. McGoldrick, J. Giordano \& N. Garcia- 
Preto (Eds.), Ethnicity and Family Therapy (pp. 629-640) (3rd Ed.). New York: The Guilford Press.

Ball, D., Tornaría, M., Masjuan, N., Trápaga, A., Arca, D., Scafarelli, L., \& Feibuscheurez, A. (2009). Escala de Evaluación del Funcionamiento Familiar -FACES IV-: Proceso de Adaptación a Motevideo, Uruguay. Ciencias Psicológicas, 3(1), 43-56.

Baiocco, R., Cacioppo, M., Laghi, F., \& Tafà, M. (2013). Factorial and Construct Validity of FACES IV among Italian Adolescents. Journal of Child and Family Studies, 22, 962-970. https://doi.org/10.1007/s10826-012-9658-1

Beaton, D. E., Bombardier, C., Guillemin, F., \& Ferraz, M. B. (2000). Guidelines for the Process of Cross-Cultural Adaptation of Self-Report Measures. SPINE, 25(24), 31863191. https://doi.org/10.1097/00007632-200012150-00014

Beavers, W. R. (1982). Healthy, mid-range, and severely dysfunctional families. In F. Walsh (Ed.), Normal family processes (pp. 115-141). New York: Guilford.

Beavers, W. R., \& Hampson, R. B. (1990). Successful families: Assessment and intervention. New York: Norton.

Beavers, W. R., \& Hampson, R. B. (1993). Measuring Family Competence: The Beavers Systems Model. In F. Walsh (Ed.), Normal Family Processes (2 $2^{\text {nd }}$ ed.) (pp. 73-103). New York: The Guilford Press.

Beavers, W. R., \& Hampson, R. B. (2000). The Beavers Systems Model of Family Functioning. Journal of Family Therapy, 22, 128-143. https://doi.org/10.1111/1467$\underline{6427.00143}$

Beavers, W. R., Hampson, R., \& Hulgus, Y. (1985). Commentary: The Beavers systems approach to family assessment. Family Process, 24, 398-405. https://doi.org/10.1111/j.1545-5300.1985.00398.x 
Carvalho, J. C., Freitas, P. P., Leuschner, \& Olson, D. H. (2014). Healthy functioning in families with a schizophrenic patient. Journal of Family Psychotherapy, 25 (1), 1-11. https://doi.org/10.1080/08975353.2014.881685

Fisher, L. (1982). Transactional theories but individual assessment: a frequent discrepancy in family research. Family Process, 21 (3), 313-320. https://doi.org/10.1111/j.1545$\underline{5300.1982 .00313 . x}$

Gomes, H. M. S., Peixoto, F., \& Gouveia-Pereira, M. (2019). Portuguese validation of the family adaptability and cohesion evaluation scale - FACES IV. Journal of Family Studies, 25 (4), 477-494. https://doi.org/10.1080/13229400.2017.1386121

Good, M. D., Smilkstein, G., Good, B. J., Shaffer, T., \& Arons T. (1979). The family APGAR Index: A study of construct validity. The Journal of Family Practice, 8(3), 577-582.

Green, R. G., \& Bagarozzi, D A. (1987). Self-report measures of family competence. The American Journal of Family Therapy, 15(2), 163-168. https://doi.org/10.1080/01926188708250669

Grotevant, H. D., \& Carlson, C. I. (1989). Family Assessment: A guide to methods and measures. New York: The Guilford Press.

Kashani, J. H., Allan, W. D., Dahlmeier, J. M., Rezvani, M., \& Reid, J. C. (1995). An examination of family functioning utilizing the circumplex model in psychiatrically hospitalized children with depression. Journal of Affective Disorders, 35, 65-73. https://doi.org/10.1016/0165-0327(95)00042-L

Kouneski, E. (2000). The Family Circumplex Model, FACES II and FACES III: Overview of Research and Applications. Retrieved from www.facesiv.com

Koutra, K., Triliva, S., Roumeliotaki, T., Lionis, C., \& Vygontzas, N. (2012). Cross-cultural adaptation and validation of the Greek version of the family adaptability and cohesion 
evaluation scales IV Package (FACES IV Package). Journal of Family Issues, 34(12), 1647-1672. https://doi.org/10.1177/2F0192513X12462818

Margasiński, A. (2015). The Polish adaptation of FACES IV-SOR. Polish Journal of Applied Psychology, 13(1), 43-66. https://doi.org/10.1515/pjap-2015-0025

Mazaheri, M., Habibi, M., \& Ashori, A. (2014). Psychometric properties of Persian version of the Family Adaptability and Cohesion Evaluation Scales (FACES-IV). Iranian Journal of Psychiatry and Clinical Psychology, 19(4), 314-325. http://ijpcp.iums.ac.ir/article-1-2092-en.html

McGoldrick, M., Carter, B., \& Garcia-Preto, N. (2014). Overview: The life cycle in its changing context: Individual, family, and social perspectives. In M. McGoldrick, B. Carter, \& N. Garcia-Preto (Eds.), The expanded family life cycle: Individual, family, social perspectives (pp. 1-19). Essex: Pearson.

Mirnics, Z., Vargha, A., Tóth, M. \& Bagdy, E. (2010). Cross-cultural applicability of FACES IV. Journal of Family Psychotherapy, 21, 17-33. https://doi.org/10.1080/08975351003618577

OECD. (2019). Education at a glance 2019: OECD Indicators. Paris: OECD Publishing. https://dx.doi.org/10.1787/f8d7880d-en

Olson, D. H. (1986). Circumplex Model VII: Validation studies and FACES III. Family Process, 25(3), 337-351. https://doi.org/10.1111/j.1545-5300.1986.00337.x

Olson, D. H. (1993). Circumplex Model of marital and family systems: Assessing family functioning. In F. Walsh (Ed.), Normal family processes (2 ${ }^{\text {nd }}$ ed.) (pp. 104-137). New York: The Guilford Press.

Olson, D. H. (2011). FACES IV and the Circumplex Model: Validation study. Journal of 
Marital \& Family Therapy, 3(1), 64-80. https://doi.org/10.1111/j.1752$\underline{0606.2009 .00175 . x}$

Olson, D. H. (n.d.). Guidelines for Translating FACES IV Package. Retrieved from $\underline{\text { www.facesiv.com }}$

Olson, D. H., Bell, R., \& Portner, J. (1978). Family adaptability and cohesion evaluation scales. Unpublished manuscript, Department of Family Social Science, University of Minnesota, St. Paul.

Olson, D. H. \& Gorall, D. M. (2003). Circumplex Model of marital and family systems. In F. Walsh (Ed.), Normal family processes (3rd ed.) (pp. 514-547). New York: Guilford.

Olson, D. H., McCubbin, H. I., Barnes, H. L., Larsen, A. S., Muxen, M. J., \& Wilson, M. A. (1989). Families: What makes them work (updated edition). Newbury Park: Sage Publications, Inc.

Olson, D. H., Portner, J., \& Bell, R. Q. (1982). FACES II: Family Adaptability and Cohesion Evaluation Scales. St. Paul: University of Minnesota.

Olson, D. H., Portner, J., \& Lavee, Y. (1985). FACES III: Family Adaptability and Cohesion Evaluation Scales. St. Paul: University of Minnesota.

Olson, D. H., Sprenkle, D. H., \& Russell, C. S. (1979). Circumplex model of marital and family systems I: Cohesion and adaptability dimensions, family types and clinic applications. Family Process, 18(1), 3-28. https://doi.org/10.1111/j.1545$\underline{5300.1979 .00003 . x}$

Pereira, M. G., \& Teixeira, R. (2013). Portuguese validation of FACES-IV in adult children caregivers facing parental cancer. Contemporary Family Therapy, 35, 478-490. https://doi.org/10.1007/s10591-012-9216-4

Place, M., Hulsmeier, J., Brownrigg, A., \& Soulsby, A. (2005). The Family Adaptability and 
Cohesion Evaluation Scale (FACES): An instrument worthy of rehabilitation? Psychiatric Bulletin, 29, 215-218. https://doi.org/10.1192/pb.29.6.215

Portugal, S. (2011). Dádiva, família e redes sociais. In S. Portugal \& P. H. Martins (Orgs.), Cidadania, politicas públicas e redes sociais (pp. 39-53). Coimbra: Imprensa da Universidade de Coimbra.

Prange, M. E., Greenbaum, P. E., Silver, S. E., Friedman, R. M., Kutas, K., \& Duchnowski, A. J. (1992). Family functioning and psychopathology among adolescents with severe emotional disturbances. Journal of Abnormal Child Psychology, 20(1), 83-102. https://doi.org/10.1007/BF00927118

Relvas, A. P. (1996). O ciclo vital da família: Perspectiva sistémica. Porto: Edições Afrontamento.

Rivero, N., Martínez-Pampliega, A., \& Olson, D. H. (2010). Spanish adaptation of the FACES IV questionnaire: Psychometric characteristics. The Family Journal: Counselling and Therapy for Couples and Families, 18(3), 288-296. https://doi.org/10.1177/2F1066480710372084

Smilkstein, G. (1978). The Family APGAR: A proposal for a family function test and its use by physicians. The Journal of Family Practice, 6(6), 1231-1239.

Smilkstein, G., Ashworth, C., \& Montano, D. (1982). Validity and reliability of the family APGAR as a test of family function. The Journal of Family Practice, 15(2), 303-311.

Tutty, L. M. (1995). Theoretical and practical issues in selecting a measure of family functioning. Research on Social Work Practice, 5(1), 80-106. https://doi.org/10.1177\%2F104973159500500107 
Table 1.

Sociodemographic and family characteristics of participants 
Table 2.

Descriptive statistics, correlation and reliability of FACES IV scales

\begin{tabular}{|c|c|c|c|c|c|c|c|c|c|}
\hline & \multirow[b]{2}{*}{$M$} & \multirow[b]{2}{*}{$S D$} & \multirow[b]{2}{*}{$\alpha$} & \multicolumn{3}{|c|}{ Cohesion scales } & \multicolumn{3}{|c|}{ Flexibility scales } \\
\hline & & & & Enmeshed & $\begin{array}{c}\text { Balance } \\
\text { Cohesion }\end{array}$ & Disengaged & Chaotic & $\begin{array}{l}\text { Balanced } \\
\text { Flexibility }\end{array}$ & Rigid \\
\hline \multicolumn{10}{|l|}{ Cohesion scales } \\
\hline Enmeshed & 19.88 & 3.29 & .58 & - & & & & & \\
\hline $\begin{array}{l}\text { Balanced } \\
\text { Cohesion }\end{array}$ & 28.03 & 3.67 & .77 & $.19^{* *}$ & - & & & & \\
\hline Disengaged & 15.14 & 4.19 & .74 & $-.10^{* *}$ & $-.65^{*}$ & - & & & \\
\hline \multicolumn{10}{|l|}{ Flexibility scales } \\
\hline Chaotic & 15.10 & 4.21 & .73 & $.08^{* *}$ & $-.44^{* *}$ & $.51^{* *}$ & - & & \\
\hline $\begin{array}{l}\text { Balanced } \\
\text { Flexibility }\end{array}$ & 26.06 & 3.61 & .64 & $.18^{* *}$ & $.72^{* *}$ & $-.52^{* *}$ & $-.39^{* *}$ & - & \\
\hline Rigid & 20.39 & 3.99 & .65 & $.41^{* *}$ & 0.05 & $.13^{* *}$ & 0.02 & $.14^{* *}$ & - \\
\hline
\end{tabular}


Table 3.

Correlation of FACES IV scales with validation scales

\begin{tabular}{lccc} 
& \multicolumn{2}{c}{ Validation Scales } \\
\cline { 2 - 3 } FACES IV Scales & $\begin{array}{c}\text { SFI-II } \\
\text { (Health/Competence } \\
\text { subscale) }\end{array}$ & FSS & APGAR \\
\hline Cohesion scales & & $.089^{* *}$ & .002 \\
Enmeshed & $-.175^{* *}$ & $.624^{* *}$ & $.135^{* *}$ \\
Balanced cohesion & $-.709^{* *}$ & $-.527^{* *}$ & $-.171^{* *}$ \\
Disengaged & $.637^{* *}$ & $-.367^{* *}$ & $-.148^{* *}$ \\
Flexibility scales & & $.565^{* *}$ & $.109^{* *}$ \\
Chaotic & $.477^{* *}$ & $-.060^{*}$ & -.004 \\
Balanced flexibility & $-.622^{* *}$ & & $* .05 ; * *<<.01$
\end{tabular}


Table 4.

Sociodemographic differences (mean and standard deviation) for FACES IV scales

\begin{tabular}{|c|c|c|c|c|c|c|}
\hline & \multicolumn{6}{|c|}{ FACES IV scales } \\
\hline & \multicolumn{3}{|c|}{ Cohesion scales } & \multicolumn{3}{|c|}{ Flexibility scales } \\
\hline & Enmeshed & $\begin{array}{l}\text { Balanced } \\
\text { cohesion }\end{array}$ & Disengaged & Chaotic & $\begin{array}{c}\text { Balanced } \\
\text { flexibility }\end{array}$ & Rigid \\
\hline & $M(S D)$ & $M(S D)$ & $M(S D)$ & $M(S D)$ & $M(S D)$ & $M(S D)$ \\
\hline \multicolumn{7}{|l|}{ Gender } \\
\hline Male & $19.74(3.27)$ & $27.74(3.60)$ & $15.52(4.15)$ & $15.26(4.28)$ & $26.02(3.62)$ & $20.61(4.08)$ \\
\hline Female & $29.00(3.03)$ & $28.28(3.71)$ & $14.82(4.21)$ & $14.96(4.16)$ & $26.09(3.60)$ & $20.21(3.91)$ \\
\hline t (sig.) & $\begin{array}{l}-1.325 \\
(.186)\end{array}$ & $-2.445(.015)^{*}$ & $2.728(.006)^{* *}$ & $.672(.250)$ & $-.290(.772)$ & $1.648(.101)$ \\
\hline \multicolumn{7}{|l|}{ Age } \\
\hline$\leq 24^{1}(n=340)$ & $19.49(3.28)$ & $27.68(3.93)$ & $15.72(4.43)$ & $15.36(4.36)$ & $25.59(3.82)$ & $20.70(4.01)$ \\
\hline $25-34^{2}(n=162)$ & $19.67(3.17)$ & $28.26(3.46)$ & $14.40(4.09)$ & $15.08(4.41)$ & $26.20(3.47)$ & $19.75(4.07)$ \\
\hline $35-44^{3}(n=179)$ & $20.45(3.27)$ & $28.82(3.41)$ & $13.94(3.50)$ & $14.35(3.77)$ & $26.91(3.42)$ & $20.72(3.89)$ \\
\hline $45 \geq^{4}(n=401)$ & $20.06(3.31)$ & $27.89(3.59)$ & $15.50(4.17)$ & $15.21(4.17)$ & $26.02(3.51)$ & $20.24(3.97)$ \\
\hline$F /$ Welch's $F_{(3,1081)}$ & $4.07 * *$ & $4.24 * *$ & $17.14 * *$ & 2.44 & $5.39 * *$ & $2.68^{\mathrm{ns}}$ \\
\hline Tukey HSD / Games-Howell & 1 vs. 3 & vs. 3 & $\begin{array}{l}1 \text { vs. } 2 ; 1 \text { vs. } \\
3 ; 2 \text { vs. } 3 ; 2 \\
\text { vs. } 4 ; 3 \text { vs. } 4\end{array}$ & 1 vs. 3 & $\begin{array}{l}1 \text { vs. } 3 ; 3 \\
\text { vs. } 4\end{array}$ & \\
\hline \multicolumn{7}{|l|}{ Employment status } \\
\hline $\begin{array}{l}\text { Working/Employed }{ }^{1}(n= \\
681)\end{array}$ & $20.01(3.25)$ & $28.34(3.48)$ & $14.73(3.97)$ & $14.90(4.19)$ & $26.38(3.51)$ & $20.23(3.99)$ \\
\hline $\operatorname{Student}^{2}(n=322)$ & $19.49(3.27)$ & $27.58(3.99)$ & $15.77(4.54)$ & $15.39(4.35)$ & $25.55(3.79)$ & $20.61(3.97)$ \\
\hline Unemployed $^{3}(n=41)$ & $20.05(3.50)$ & $27.24(3.61)$ & $15.71(3.70)$ & $15.05(3.58)$ & $24.71(3.41)$ & $20.80(3.55)$ \\
\hline $\operatorname{Retired}^{4}(n=35)$ & $20.89(3.37)$ & $27.46(3.67)$ & $16.74(4.72)$ & $16.20(4.01)$ & $26.11(3.17)$ & $21.03(4.72)$ \\
\hline$F /$ Welch's $F_{(3,1078)}$ & $3.07 * \mathrm{~s}$ & $4.14 * *$ & $6.63 * *$ & $1.85^{\mathrm{ns}}$ & $5.93 * *$ & $1.12^{\mathrm{ns}}$ \\
\hline Tukey HSD / Games-Howell & & 1 vs. 2 & 1 vs. $2 ; 1$ vs. 4 & & 1 vs. 2 & \\
\hline \multicolumn{7}{|l|}{ Education } \\
\hline$\leq 1^{\text {st }} \operatorname{Cycle}^{1}(n=72)$ & $21.17(3.81)$ & $27.07(3.60)$ & $16.68(4.91)$ & $15.68(4.35)$ & $24.93(3.57)$ & $21.67(4.87)$ \\
\hline $\begin{array}{l}2^{\text {nd }} \text { Cycle, } 3^{\text {rd }} \text { Cycle and } \\
\text { Secondary }^{2}(n=728)\end{array}$ & $19.74(3.25)$ & $27.70(3.60)$ & $15.37(4.12)$ & $15.23(4.26)$ & $25.88(3.61)$ & $20.54(3.94)$ \\
\hline $\begin{array}{l}\text { Higher Education }{ }^{3}(n= \\
280)\end{array}$ & $19.93(3.19)$ & $29.13(3.49)$ & $14.17(3.99)$ & 14. $63(4.03)$ & $26.79(3.51)$ & $19.66(3.78)$ \\
\hline$F /$ Welch's $F_{(2,1079)}$ & $6.23 * *$ & $18.59 * *$ & $13.72 * *$ & $2.76^{\mathrm{ns}}$ & $18.59 * *$ & $8.94 * *$ \\
\hline Tukey HSD / Games-Howell & $\begin{array}{l}1 \text { vs. } 2 ; 1 \text { vs. } \\
3\end{array}$ & 1 vs. $3 ; 2$ vs. 3 & 1 vs. $2 ; 1$ vs. 3 & & $\begin{array}{l}1 \text { vs. } 3 ; 2 \\
\text { vs. } 3\end{array}$ & $\begin{array}{l}1 \text { vs. } 3 ; 2 \\
\text { vs. } 3\end{array}$ \\
\hline
\end{tabular}


Table 5.

Perception of family functioning according to family subsystem membership and life cycle stage

\begin{tabular}{|c|c|c|c|c|c|c|}
\hline & \multicolumn{6}{|c|}{ FACES IV scales } \\
\hline & \multicolumn{3}{|c|}{ Cohesion scales } & \multicolumn{3}{|c|}{ Flexibility scales } \\
\hline & Enmeshed & $\begin{array}{l}\text { Balanced } \\
\text { cohesion }\end{array}$ & Disengaged & Chaotic & $\begin{array}{c}\text { Balanced } \\
\text { flexibility }\end{array}$ & Rigid \\
\hline & $M(S D)$ & $M(S D)$ & $M(S D)$ & $M(S D)$ & $M(S D)$ & $M(S D)$ \\
\hline \multicolumn{7}{|l|}{ Family subsystem } \\
\hline Parent $^{1}(\mathrm{n}=594)$ & $\begin{array}{l}20.20 \\
(3.34)\end{array}$ & $\begin{array}{l}28.28 \\
(3.49)\end{array}$ & $14.82(4.02)$ & $\begin{array}{l}14.87 \\
(4.09)\end{array}$ & $26.33(3.54)$ & $\begin{array}{l}20.36 \\
(4.06)\end{array}$ \\
\hline Child $^{2}(\mathrm{n}=390)$ & $\begin{array}{l}19.34 \\
(3.14)\end{array}$ & $\begin{array}{l}27.60 \\
(3.85)\end{array}$ & $15.67(4.44)$ & $\begin{array}{l}15.31 \\
(4.40)\end{array}$ & $25.52(3.74)$ & $\begin{array}{l}20.47 \\
(3.84)\end{array}$ \\
\hline Couple $^{3}(\mathrm{n}=99)$ & $\begin{array}{l}20.08 \\
(3.34)\end{array}$ & $\begin{array}{l}28.24 \\
(3.82)\end{array}$ & $15.03(3.96)$ & $\begin{array}{l}15.66 \\
(4.15)\end{array}$ & $26.51(3.29)$ & $\begin{array}{l}20.27 \\
(4.20)\end{array}$ \\
\hline$F /$ Welch's $F_{(2,1080)}$ & $8.30 * *$ & $4.30 *$ & $4.93 * *$ & $2.24^{\mathrm{ns}}$ & $6.89 * *$ & $0.14^{\mathrm{ns}}$ \\
\hline Tukey HSD / Games-Howell & 1 vs. 2 & 1 vs. 2 & 1 vs. 2 & & $\begin{array}{l}1 \text { vs. } 2 ; 2 \\
\text { vs. } 3\end{array}$ & \\
\hline \multicolumn{7}{|l|}{ Life cycle stage } \\
\hline $\begin{array}{l}\text { Young couple without } \\
\text { children }^{1}(\mathrm{n}=60)\end{array}$ & $\begin{array}{l}19.38 \\
(2.98)\end{array}$ & $\begin{array}{l}28.78 \\
(3.25)\end{array}$ & $14.58(3.85)$ & $\begin{array}{l}15.57 \\
(3.83)\end{array}$ & $26.93(3.13)$ & $\begin{array}{l}20.53 \\
(4.46)\end{array}$ \\
\hline Childbearing stage $^{2}(\mathrm{n}=52)$ & $\begin{array}{l}20.08 \\
(3.69)\end{array}$ & $\begin{array}{l}28.88 \\
(3.37)\end{array}$ & $14.31(4.59)$ & $\begin{array}{l}14.62 \\
(4.38)\end{array}$ & $26.35(3.65)$ & $\begin{array}{l}19.12 \\
(4.40)\end{array}$ \\
\hline $\begin{array}{l}\text { Family with school-age } \\
\text { children }^{3}(\mathrm{n}=83)\end{array}$ & $\begin{array}{l}20.58 \\
(3.41)\end{array}$ & $\begin{array}{l}29.02 \\
(3.68)\end{array}$ & $13.35(3.40)$ & $\begin{array}{l}15.01 \\
(3.81)\end{array}$ & $26.73(3.30)$ & $\begin{array}{l}20.39 \\
(3.89)\end{array}$ \\
\hline $\begin{array}{l}\text { Family with adolescents }{ }^{4}(\mathrm{n} \\
=166)\end{array}$ & $\begin{array}{l}20.39 \\
(3.27)\end{array}$ & $\begin{array}{l}27.78 \\
(3.57)\end{array}$ & $15.04(4.13)$ & $\begin{array}{l}14.55 \\
(3.91)\end{array}$ & $26.66(3.22)$ & $\begin{array}{l}21.17 \\
(3.82)\end{array}$ \\
\hline $\begin{array}{l}\text { Family with adult children } \\
(\mathrm{n}=722)\end{array}$ & $\begin{array}{l}19.71 \\
(3.25)\end{array}$ & $\begin{array}{l}27.85 \\
(3.71)\end{array}$ & $15.48(4.23)$ & $\begin{array}{l}15.23 \\
(4.34)\end{array}$ & $25.75(3.73)$ & $\begin{array}{l}20.30 \\
(3.95)\end{array}$ \\
\hline$F /$ Welch's $F_{(5,1078)}$ & $2.83^{*}$ & $3.52 *$ & $5.89 * *$ & $1.25^{\mathrm{ns}}$ & $4.23 * *$ & $3.04 *$ \\
\hline Tukey HSD / Games-Howell & & 3 vs. 5 & $\begin{array}{l}3 \text { vs. } 4 ; 3 \text { vs. } \\
5\end{array}$ & & 3 vs. 4 & 2 vs. 4 \\
\hline
\end{tabular}


Table 6.

Discriminant analysis of "problem and non-problem" families (percent accuracy in discriminating groups)

\begin{tabular}{|c|c|c|c|c|}
\hline FACES IV Scales & $\begin{array}{c}\text { Top versus bottom } \\
50 \% \text { on SFI (HC) and } \\
\text { FSS }\end{array}$ & $\begin{array}{c}\text { Top versus bottom } \\
40 \% \text { on SFI }(\mathrm{HC}) \text { and } \\
\text { FSS }\end{array}$ & $\begin{array}{l}\text { Top versus bottom } \\
50 \% \text { on APGAR }\end{array}$ & $\begin{array}{l}\text { Top versus bottom } \\
40 \% \text { on APGAR }\end{array}$ \\
\hline$n$ for each group & $\begin{array}{c}\text { Top }=370 \\
\text { Bottom }=391\end{array}$ & $\begin{array}{c}\text { Top }=289 \\
\text { Bottom }=293\end{array}$ & $\begin{array}{c}\text { Top }=533 \\
\text { Bottom }=357\end{array}$ & $\begin{array}{c}\text { Top }=286 \\
\text { Bottom }=357\end{array}$ \\
\hline \multicolumn{5}{|l|}{ Cohesion scales } \\
\hline Enmeshed & 53.7 & 52.4 & 53.8 & 51.8 \\
\hline Balanced cohesion & 80.6 & 85.1 & 74.2 & 72.3 \\
\hline Disengaged & 76.7 & 81.4 & 67.3 & 68.1 \\
\hline \multicolumn{5}{|l|}{ Flexibility scales } \\
\hline Chaotic & 67.3 & 71.6 & 64.7 & 64.2 \\
\hline Balanced flexibility & 76.2 & 80.2 & 73.9 & 72.8 \\
\hline Rigid & 52.0 & 52.1 & 50.4 & 50.9 \\
\hline Six scales together & 84.4 & 86.6 & 72.4 & 74.6 \\
\hline \multicolumn{5}{|l|}{ Dimension ratios } \\
\hline Cohesion ratio & 80.0 & 84.5 & 69.3 & 70.0 \\
\hline Flexibility ratio & 76.0 & 80.9 & 69.9 & 71.5 \\
\hline Total ratio & 81.1 & 85.1 & 74.2 & 72.3 \\
\hline \multicolumn{5}{|l|}{ Validation scales } \\
\hline SFI (SC) & NA & NA & 78.8 & 79.3 \\
\hline SFF & NA & NA & 78.6 & 81.5 \\
\hline APGAR & 78.4 & 84.3 & NA & NA \\
\hline
\end{tabular}

